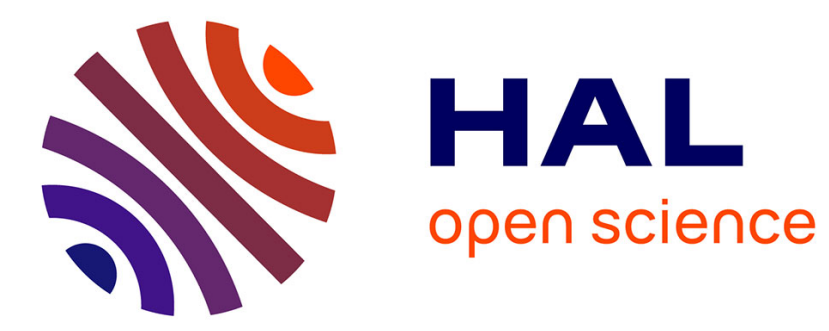

\title{
Optimization of heat and mass transfers in counterflow corrugated-plate liquid-gas exchangers used in a greenhouse dehumidifier
}

\author{
N. Bentounes, A. Jaffrin
}

\section{- To cite this version:}

N. Bentounes, A. Jaffrin. Optimization of heat and mass transfers in counterflow corrugated-plate liquid-gas exchangers used in a greenhouse dehumidifier. European Physical Journal: Applied Physics, 1998, 3, pp.295-308. hal-02695737

\section{HAL Id: hal-02695737 \\ https://hal.inrae.fr/hal-02695737}

Submitted on 1 Jun 2020

HAL is a multi-disciplinary open access archive for the deposit and dissemination of scientific research documents, whether they are published or not. The documents may come from teaching and research institutions in France or abroad, or from public or private research centers.
L'archive ouverte pluridisciplinaire HAL, est destinée au dépôt et à la diffusion de documents scientifiques de niveau recherche, publiés ou non, émanant des établissements d'enseignement et de recherche français ou étrangers, des laboratoires publics ou privés. 


\title{
Optimization of heat and mass transfers in counterflow corrugated-plate liquid-gas exchangers used in a greenhouse dehumidifier
}

\author{
N. Bentounes and A. Jaffrin ${ }^{a}$ \\ URIH-INRA, Route des Colles, Sophia Antipolis, 06410 Biot, France
}

Received: 11 December 1997 / Revised: 15 June 1998 / Accepted: 18 June 1998

\begin{abstract}
Heat and mass transfers occuring in a counterflow direct contact liquid-gas exchanger determine the performance of a new greenhouse air dehumidifier designed at INRA. This prototype uses triethylene glycol (TEG) as the desiccant fluid which extracts water vapor from the air. The regeneration of the TEG desiccant fluid is then performed by direct contact with combustion gas from a high efficiency boiler equipped with a condensor. The heat and mass transfers between the thin film of diluted TEG and the hot gas were simulated by a model which uses correlation formula from the literature specifically relevant to the present cross-corrugated plates geometry. A simple set of analytical solutions is first derived, which explains why some possible processes can clearly be far from optimal. Then, more exact numerical calculations confirm that some undesirable water recondensations on the upper part of the exchanger were limiting the performance of this prototype. More suitable conditions were defined for the process, which lead to a new design of the apparatus. In this second prototype, a gas-gas exchanger provides dryer and cooler gas to the basis of the regenerators, while a warmer TEG is fed on the top. A whole range of operating conditions was experimented and measured parameters were compared with numerical simulations of this new configuration: recondensation did not occur any more. As a consequence, this second prototype was able to concentrate the desiccant fluid at the desired rate of $20 \mathrm{~kg} \mathrm{H}_{2} \mathrm{O} /$ hour, under temperature and humidity conditions which correspond to the dehumidification of a $1000 \mathrm{~m}^{2}$ greenhouse heated at night during the winter season.
\end{abstract}

PACS. 44.25. $+\mathrm{f}$ Convective and constrained heat transfer

\section{Nomenclature}

\section{Symbol meaning}

The symbols used in the present study are described in Table 1.

\section{Subscripts}

g: gas; l: liquid; i: input; o: output.

\section{Dimensionless numbers and groups}

$$
L e=\frac{\alpha}{D_{c}} \quad \text { Lewis Number. }
$$

$N z=\frac{K_{m} \Sigma z}{\mathcal{G}}$ Number of unit transfer along the distance $\mu=\frac{\mathcal{G} C^{*}}{\mathcal{L} C p_{l}} \quad$ Gas/liquid energy flow ratio.

\footnotetext{
a e-mail: jaffrin@antibes.inra.fr
}

\begin{abstract}
Abbreviations
BIG Immersed Gas Burner, from Giordano Industries, France.

INRA Institut National de la Recherche Agronomique.

TEG Triethylene glycol.

Pad Cellulosic cross corrugated plate complex.
\end{abstract}

\section{Introduction}

Direct contact heat and mass transfers between a humid gas and a dessicant fluid are the key process which determines the performance of an open cycle air dehumidifier. Air dehumidification by means of desiccant fluids has been considered for various applications in the past. One application concerns space cooling using a solar heat source [1-4]: in that case, air is first dried, cooled at ambiance, and then humidified again in cooling pads [5-7]. This absorption system can replace compression coolers when solar heat is available [8-10]. Another application concerns the reduction of humidity in large spaces when electric heat pumps are too expensive: agricultural greenhouses in winter time are a typical example $[11,12]$. 
Table 1. Meaning of the symbols with their corresponding units.

\begin{tabular}{|lll|}
\hline Symbol & Meaning & Unit \\
\hline$C p$ & Massic heat capacity & {$\left[\mathrm{J} \mathrm{kg}^{-1} \mathrm{~K}^{-1}\right]$} \\
$C^{*}$ & Effective heat capacity & {$\left[\mathrm{J} \mathrm{kg}^{-1} \mathrm{~K}^{-1}\right]$} \\
$D c$ & Diffusion coefficient (water vapor in gas) & {$\left[\mathrm{m}^{2} \mathrm{~s}^{-1}\right]$} \\
$\mathcal{G}$ & Dry gas mass flow per unit surface & {$\left[\mathrm{kg} \mathrm{m}^{-2} \mathrm{~s}^{-1}\right]$} \\
$h^{*}, h_{\text {sat }}(T l)$ & Enthalpy of gas saturated at the liquid temperature & {$\left[\mathrm{J} \mathrm{kg}^{-1}\right]$} \\
$h_{\text {sat }}(T g)$ & Saturated gas enthalpy & {$\left[\mathrm{J} \mathrm{kg}^{-1}\right]$} \\
$h_{g}$ & Gas enthalpy & {$\left[\mathrm{J} \mathrm{kg}^{-1}\right]$} \\
$K$ & Convective coefficient & {$\left[\mathrm{W} \mathrm{m}^{-2} \mathrm{~K}^{-1}\right]$} \\
$K_{m}$ & Convective coefficient for mass transfer & {$\left[\mathrm{kg} \mathrm{s}^{-1} \mathrm{~m}^{-2}\right]$} \\
$K_{m c}$ & Convective coefficient for concentration & {$\left[\mathrm{m} \mathrm{s}^{-1}\right]$} \\
$\mathcal{L}$ & Liquid mass flow par unit surface & {$\left[\mathrm{kg} \mathrm{m}^{-2} \mathrm{~s}^{-1}\right]$} \\
$L v$ & Water latent heat of evaporation & {$\left[\mathrm{J} \mathrm{kg}^{-1}\right]$} \\
$T$ & Temperature & {$\left[\mathrm{K}^{-1}\right]$} \\
$T_{\text {inv }}$ & Temperature invariant value & {$\left[\mathrm{K}^{-1}\right]$} \\
$w$ & Gas humidity content & {$\left[\mathrm{kg} \mathrm{kg}_{\text {gas }}^{-1}\right]$} \\
$w^{*}, w_{\text {sat }}$ & Saturated gas humidity content & {$\left[\mathrm{kg} \mathrm{kg}_{\text {gas }}^{-1}\right]$} \\
$X_{\text {teg }}$ & Concentration of the TEG solution & {$[\%]$} \\
$\alpha$ & Heat diffusivity of gas & {$\left[\mathrm{m}^{2} \mathrm{~s}^{-1}\right]$} \\
$\varepsilon$ & Efficiency & {$[\%]$} \\
$\Sigma$ & Pad surface per unit volume & {$\left[\mathrm{m}^{2} \mathrm{~m}^{-3}\right]$} \\
\hline
\end{tabular}

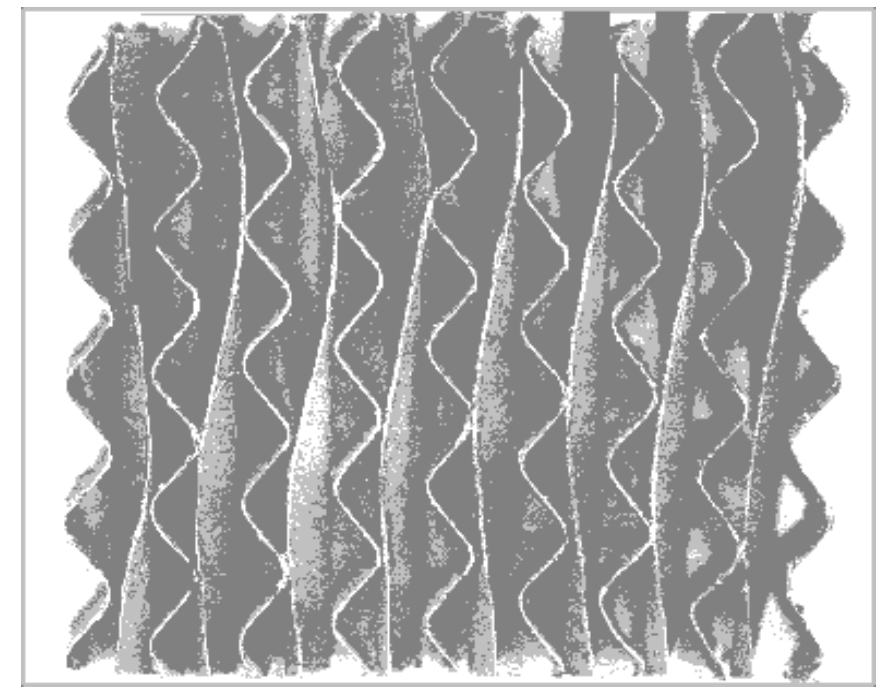

Fig. 1. Picture of a commercial pad made with corrugated cellulosic plates.

A prototype air dehumidifier for greenhouse applications has been developed by the INRA [13-15]. Like most previous systems developed for space cooling, it operates as an open cycle chemical heat pump. The thermodynamic fluid is the water contained in the air and the absorber is an organic desiccant fluid: a solution of triethylene glycol (TEG) at about $90 \%$ grade. Humid air from the greenhouse is dried by passing horizontally through a pad (a trickle exchanger made of cross corrugated adjacent cellulosic plates, as shown in Fig. 1) continuously wetted by the desiccant fluid at ambient temperature (from 10 to $\left.20^{\circ} \mathrm{C}\right)[14]$.

While the air loses humidity, the desiccant TEG fluid is progressively diluted by water condensates. To maintain the drying capacity of TEG, it is necessary to reconcentrate the TEG solution on line. This is done by a regenerator, operating at ambient pressure, where water is evaporated from a warmed up TEG solution in direct contact with dry and hot gas. The hot gas comes from a high efficiency immersed boiler "BIG" (Giordano Industries; Aubagnes, France), and at the end of the cycle, the hot and humid gas loses its excess water content in a condenser. This condenser is cooled by return water from the low temperature greenhouse heating coil. At this stage, the enthalpy of the water vapor extracted from the air is recovered and participates to the greenhouse heating.

Typical temperatures are as follows. Hot gas, at $400{ }^{\circ} \mathrm{C}$ from the immersed burner, is first used to preheat near $70^{\circ} \mathrm{C}$ a cold $\left(15^{\circ} \mathrm{C}\right)$ TEG solution; the hot gas is further cooled down (to $90^{\circ} \mathrm{C}-130^{\circ} \mathrm{C}$ ) by mixing with cold gas from the stack. After gaining water vapor from the TEG solution, the hot gas leaves the regenerators around $70^{\circ} \mathrm{C}$ and is finally washed and cooled down below $40^{\circ} \mathrm{C}$ by return water from the greenhouse coil. The greenhouse heating coil is fed by warm water coming from the boiler in the $45-55^{\circ} \mathrm{C}$ temperature range, depending on the actual heating loads.

The latent heat of the humidity extracted from the air is thus entirely recovered by the water returning to the boiler, and the enthalpy content of the smokes leaving the stack is not modified by the TEG regeneration process. Therefore, the dehumidifying thermodynamical loop does 


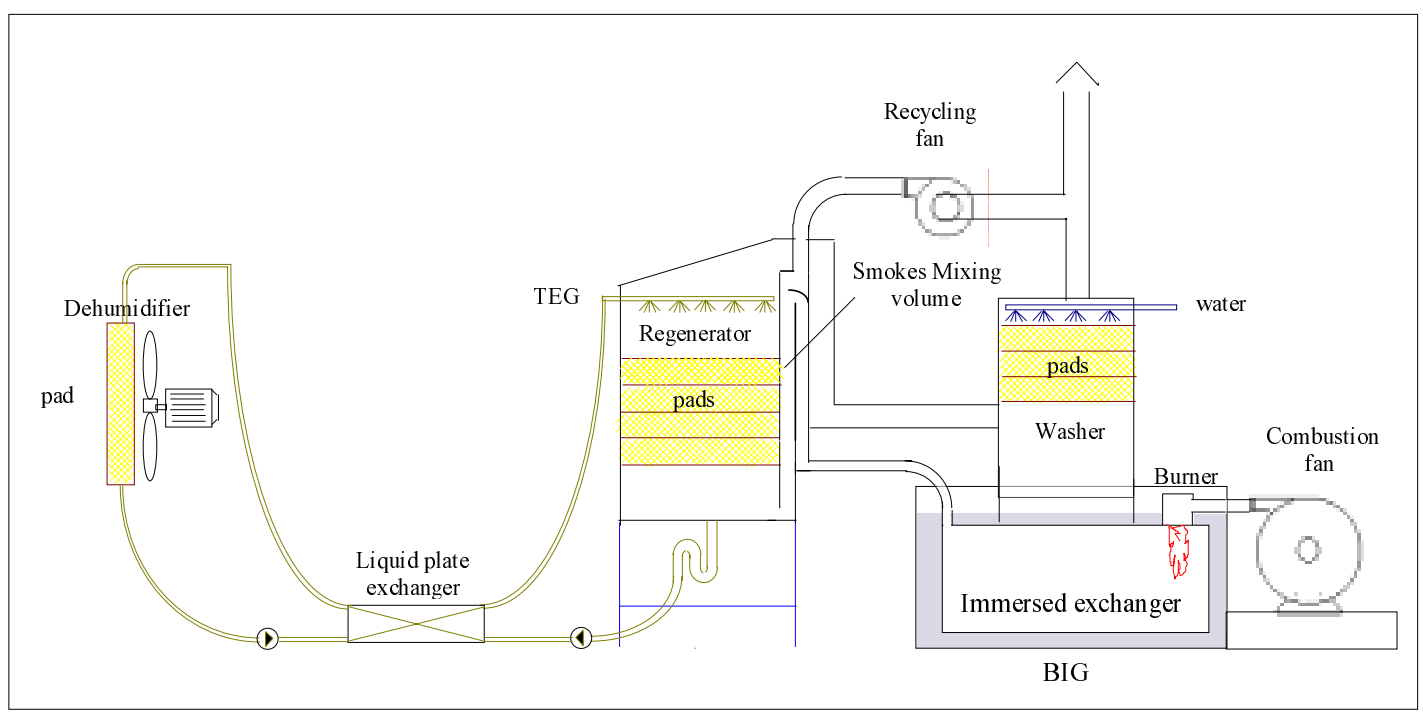

Fig. 2. First version of dehumidifier prototype by INRA.

not decrease the performance of the boiler, but it reduces the enthalpic losses by restricting the necessary air leaks intended to keep the heated greenhouse dry.

The first INRA prototype dehumidifier, shown in Figure 2, was designed to operate with a $150 \mathrm{~kW}$ condensation boiler typically dimensioned for a $1000 \mathrm{~m}^{2}$ greenhouse. The figure shows three separate components:

a) the dehumidifier; vertical cellulosic pads fed from above with cold TEG solution and crossed horizontally by air blown from the greenhouse;

b) the regenerator; horizontal cellulosic pads crossed with ascending hot gas and a warm TEG solution flowing down, in a counterflow mode;

c) the gas washer; horizontal cellulosic pads, crossed with ascending warm and humid gas while water is sprayed on the top, recover a large part of the gas enthalpy.

Experimental tests were performed on this prototype to study its performance [13].

\section{Experimental results obtained on prototype No 1}

The regenerator and the gas washer were tested apart from the dehumidification pads, for the sake of simplicity. The dehumidifier, which delivers cold and diluted TEG was replaced by a tank containing a large mass $(60 \mathrm{~kg})$ of diluted TEG solution, initially at $90 \%$ grade and ambiant temperature. A pump feeds the TEG solution at the top of the regenerators pads; the TEG trickles down by gravity while its concentration raises (by typically $1 \%$ ). The tank is placed on a precision scale $(100 \mathrm{~kg}$ range with a resolution of $10 \mathrm{~g}$ ), so that periodic records give access to the water evaporation rate from the TEG. An independent estimate is obtained by measuring the gas humidity before and after the regeneration process, for a fixed flow

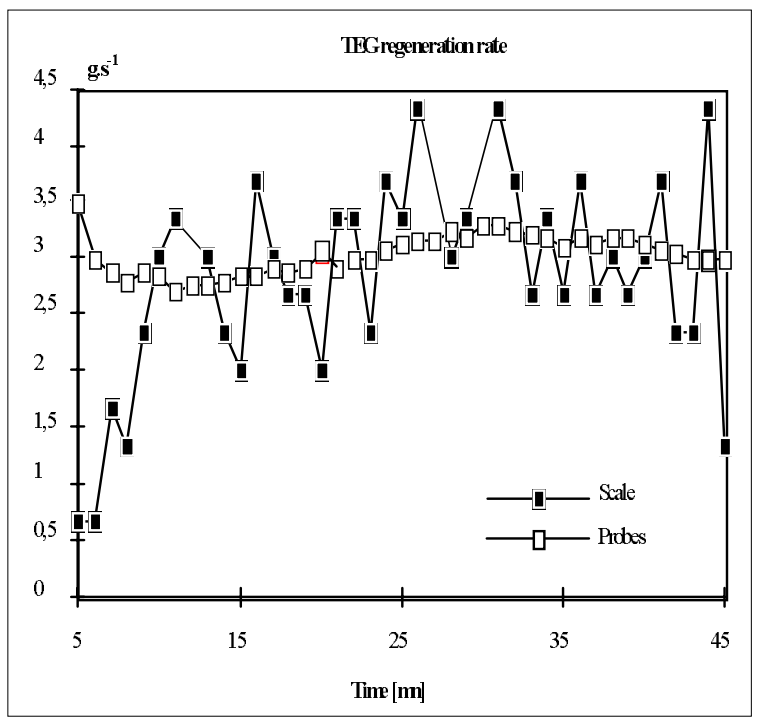

Fig. 3. TEG regeneration rate deduced from weight and from psychrometric measurements on first prototype.

rate. Figure 3 compares the two estimates, which are in fair agreement in spite of strong weight fluctuations due to the turbulent TEG return flow to the tank. Most runs performed on this first prototype indicated a maximum regeneration rate near $3 \mathrm{~g} \mathrm{H}_{2} \mathrm{O} \mathrm{s}^{-1}$, a value obtained with the burner operating at half power $(75 \mathrm{~kW})$. This performance (corresponding to less than $11 \mathrm{~kg} / \mathrm{h}$ in dehumidifying capacity) is supposed to be just enough for a $500 \mathrm{~m}^{2}$ greenhouse. But the full rated power $(150 \mathrm{~kW})$ could not be used with the present design, a feature which clearly showed that the regenerator was not operating in optimal conditions and could not meet the dehumidification requirements of a $1000 \mathrm{~m}^{2}$ greenhouse at its maximum heat load. 


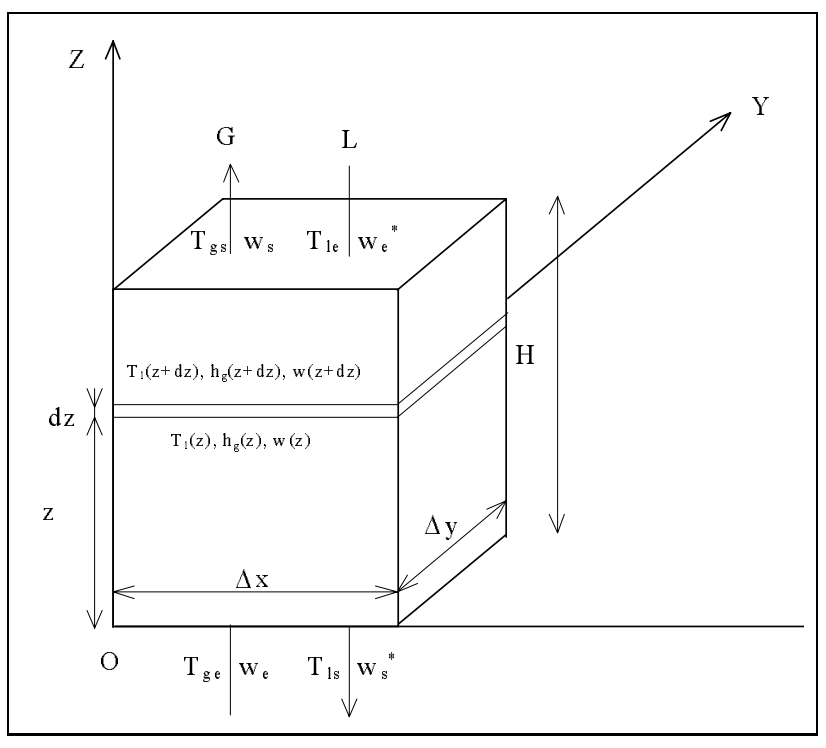

Fig. 4. Sketch of a counterflow heat and mass exchange.

\section{Modeling counterflow liquid-gas exchanges}

To understand the restricted performance of the first regenerator prototype, a detailed thermodynamic model of heat and mass transfers in the liquid-gas exchangers was constructed [17]. This model describes the vertical counterflow exchanges occurring between a falling liquid film adherent to the walls of cross-corrugated plates and an upstream of gas. It therefore applies to the regenerators, in which water is evaporated from the TEG solution by hot gas, and to the combustion gas washer in which the enthalpy of the water vapor of the gas is recovered before it goes through the stack. The purpose of the model is to help identify sub-optimal working conditions that may occur during such heat and mass transfers.

The model is derived from the works of Stevens et al. [16]. The numerical treatment is occasionally analytical, and this opportunity will be exploited; but in most circumstances, a numerical method is required to get a more precise answer. The notations are the following:

$\mathcal{G}$ dry gas massic rate by unit of surface in the $(x, y)$ plane

$\mathcal{L}$ liquid TEG massic rate by unit of surface in the $(x, y)$ plane

$\Delta x$ pad width along the $x$ direction

$\Delta y$ pad width along the $y$ direction

$d z$ height of an elementary volume of exchanger

$\Delta z$ height of a macroscopic sub-volume of exchanger

$Z$ total height of exchanger in the $z$ direction.

Useful parameters for the process are indicated in Figure 4 which represents a counterflow liquid-gas directcontact exchanger formed with piled cellulosic pads, irrigated by gravity from the top by a warm TEG solution, and fed from the bottom by an ascending stream of hot gas.

The following hypothesis are made concerning the transfers:
- the thermal inertia of the pads is neglected;

- in an elementary volume $d v=\Delta x . \Delta y . d z$, all fluid parameters stay constant; (they may only vary with the vertical coordinate $z$, at most).

Although this is not an obligation in the numerical treatment, one is generally entitled to admit, given the type of striping process considered here, that the TEG liquid mass rate $\mathcal{L}$ is not really modified by the water evaporation process. $\mathcal{L}$ will be taken as a constant throughout the exchanger. Simillarly, $C p$ values of the gas and of the liquid will be considered constant. The validity of these assumptions will be fully justified at the end, once the actual changes in temperatures and concentrations are estimated. The energy balance applied to the elementary volume $\mathrm{dv}$ reads:

$$
\mathcal{G} d h_{g}=\mathcal{L} C p_{l} d T_{l}
$$

On its own, the enthalpy change of the gas results from heat and mass transfers:

$$
\mathcal{G} d h_{g}=\mathcal{G} C p_{g} d T_{g}+\mathcal{G} L_{v} d w
$$

where the sensible heat transfer is governed by a convective coefficient $K$

$$
\mathcal{G} C p_{g} d T_{g}=K \Sigma\left(T_{l}-T_{g}\right) d z
$$

with $\Sigma$ : "pad" surface per unit volume $\left[\mathrm{m}^{2} \mathrm{~m}^{-3}\right]$. The quality of the simulation of heat transfers depends on the validity of the convective coefficient $K$ determined for the geometry of cross corrugated plates. A special care was taken [17] to determine the relevant $K$ from existing correlation formula established by Amblard [18] on the basis of similar cross corrugated plates. Similarly, the mass transfer is governed by a coefficient $K_{m}$

$$
\mathcal{G} d w=K_{m} \Sigma\left(w^{*}-w\right) d z .
$$

Both coefficients are related by the usual assumption that there is equivalence between heat and mass transfers in a boundary layer, which implies:

$$
K=K_{m} L e^{\alpha} C p_{g}
$$

where the exponent $\alpha$ is usually considered to be close to 0,567 The term $w^{*}$ stands for the limiting humidity content of the gas, supposing that the gas is saturated at the temperature of the liquid in direct contact. Thus:

$$
\mathcal{G} d h_{g}=K \Sigma\left(T_{l}-T_{g}\right) d z+K_{m} \Sigma\left(w^{*}-w\right) d z
$$

and by defining the enthalpy origin at $0{ }^{\circ} \mathrm{C}$ and zero humidity, the enthalpy of the gas saturated at the liquid temperature is then:

$$
h^{*}=C p_{g} T_{l}+L_{v} w^{*} .
$$

Equation (6) then reads:

$$
\mathcal{G} d h_{g}=K_{m} \Sigma d z\left[\left(h^{*}-h_{g}\right)+(L e-1) C p_{g}\left(T_{l}-T_{g}\right)\right]
$$


Now, it is usual, for humid air, to make the Lewis approximation: $L e \cong 1$. This simplifies the expression (8) of the energy balance into:

$$
d h_{g}=\frac{K_{m} \Sigma}{\mathcal{G}}\left(h^{*}-h_{g}\right) d z .
$$

Following Stevens et al. [16], one can get rid of the enthalpy term $h^{*}$ by using the local value $C^{*}$ of the slope of the saturation curve of the air at the temperature $T_{l}$. $C^{*}$ can be interpreted as an effective heat capacity per unit of mass:

$$
C^{*}=\frac{d h^{*}}{d T_{l}}
$$

$C^{*}$ stays constant in any sub-volume of the exchanger where the temperature and the concentration of the TEG solution stay unchanged.

With the help of equation (1), the differential element $d h^{*}$ can then be written:

$$
d h^{*}=\frac{\mathcal{G} C^{*}}{\mathcal{L} C p_{l}} d h_{g}
$$

and it transforms equation (9) into a differential equation for $\left(h_{g}-h^{*}\right)$ :

$$
d\left(h_{g}-h^{*}\right)=-\left(1-\frac{\mathcal{G} C^{*}}{L C p_{l}}\right) \frac{K_{m} \Sigma}{\mathcal{G}}\left(h_{g}-h^{*}\right) d z
$$

For the sake of simplicity, the following groups are defined:

$$
\mu=\frac{\mathcal{G} C^{*}}{\mathcal{L} C p_{l}}
$$

which will be refered to as the energetic gas/liquid flow ratio, and

$$
N=\frac{K_{m} \Sigma}{\mathcal{G}} \quad\left[\mathrm{m}^{-1}\right]
$$

which can be understood as a Number of Unit Transfer Nut per unit length $z: N=N u t / z$.

Equation (12) then takes the form:

$$
\frac{d\left(h_{g}-h^{*}\right)}{\left(h_{g}-h^{*}\right)}=-(1-\mu) N d z \text {. }
$$

In the elementary volume $d v$, the $z$ coordinate stands as the entrance for the gas, and the exit for the liquid. Conversely, $z+d z$ represents the exit for the gas and the entrance for the liquid. More generally, index $i$ will refer to input, and index $o$ to output (for the gas, the input refers to $z=0$, or to $z=z_{o}$ for a given sub-volume; for the liquid, the input refers to the upper side, $z=Z$ for the whole exchanger, or $z=z_{o}+\Delta z$ for a given sub-volume).

Integrating equation (15) over the distance $\Delta z$ over which $\mu$ stays constant, we get the enthalpy gap between the gas, supposed saturated and locally at equilibrium with the liquid, and the gas in its actual conditions, over a sub-volume $\Delta v$ :

$$
h_{g o}-h_{i}^{*}=\left(h_{g i}-h_{o}^{*}\right) e^{-(1-\mu) N \Delta z}
$$

where $N \Delta z$ is the number of unit transfer relative to the distance $\Delta z$.

Only entrance enthalpies $h_{g i}$ and $h_{i}^{*}$ are known, and equation (11) is used to get rid of $h_{o}^{*}$ :

$$
h_{i}^{*}-h_{o}^{*}=\mu\left(h_{g o}-h_{g i}\right) .
$$

So that the final equation for the counterflow exchange process reads now:

$$
h_{g o}-h_{g i}=\left(h_{i}^{*}-h_{g i}\right) \frac{1-\exp [-(1-\mu) N \Delta z]}{1-\mu \exp [-(1-\mu) N \Delta z]} .
$$

This analytical expression only holds between the entrance and the exit of a macroscopic sub-volume $\Delta v=\Delta x . \Delta y . \Delta z$ in which the term $\mu$ is supposed to stay relatively constant.

By analogy with sensible heat exchangers, one can define an efficiency coefficient $\varepsilon$ :

$$
\varepsilon=\frac{1-\exp [-(1-\mu) N \Delta z]}{1-\mu \exp [-(1-\mu) N \Delta z]}
$$

to express the enthalpy at the exit of the sub-volume as:

$$
h_{g o}=h_{g i}+\varepsilon\left(h_{i}^{*}-h_{g i}\right)
$$

Equation (4) for the absolute humidity $w$ of the gas looks similar to equation (10), but the procedure to derive $w$ is different.

By analogy, one introduces the local value $A^{*}$ of the slope to the curve of the absolute humidity $w^{*}(T)$ :

$$
A^{*}=\frac{d w^{*}}{d T_{l}} .
$$

Again, $A^{*}$ is supposed to stay relatively constant in the macroscopic sub-volume $\Delta v$ of the exchanger.

From equation (7), we can express $d w^{*}$, using equations (9) and (11), as:

$$
d w^{*}=\frac{\mu}{\left(C p_{g} / A^{*}\right)+L_{v}}\left(h_{g}-h^{*}\right) N d z .
$$

Equation (4) then combines with equation (22) to give:

$$
\begin{aligned}
& d\left(w-w^{*}\right)= \\
& \quad-\left[\left(w-w^{*}\right)-\frac{\mu}{\left(C p_{g} / A^{*}\right)+L_{v}}\left(h_{g}-h^{*}\right)\right] N d z
\end{aligned}
$$

$\left(h_{g}-h^{*}\right)$ can be explicited, using equations (16), (17) and (18), under a form which only contains known input values:

$$
h_{g}-h^{*}=\left(h_{g i}-h_{i}^{*}\right)(1-\mu) \frac{\exp [-(1-\mu) N z]}{1-\mu \exp [-(1-\mu) N z]} .
$$

Equation (23) then becomes a standard differential equation with a second member:

$$
\begin{aligned}
& \frac{d\left(w-w^{*}\right)}{d z}+\frac{K_{m} \Sigma}{\mathcal{G}}\left(w-w^{*}\right) \\
&=D\left(\frac{\exp [-(1-\mu) N z]}{1-\mu \exp [-(1-\mu) N z]}\right)
\end{aligned}
$$


where we introduced the constant $D$ :

$$
D=\frac{K_{m} \Sigma}{\mathcal{G}} \frac{\mu(1-\mu)}{\left(C p_{g} / A^{*}\right)+L_{v}}\left(h_{g i}-h_{i}^{*}\right) .
$$

The solution of equation (25), valid for $z$ inside a subrange $z_{o}$ to $z_{o}+\Delta z$, is obtained after some manipulations [17] as:

$$
\begin{aligned}
w= & w^{*}+\left[D \frac { \operatorname { e x p } ( \mu N z ) } { \mu N } F \left(\frac{\mu}{\mu-1}, 1\right.\right. \\
& \left.\left.\frac{2 \mu-1}{\mu-1}, \mu \exp [-(1-\mu) N z]\right)+E\right] \exp (-N z)
\end{aligned}
$$

where $F$ is the usual hypergeometric function.

The constant $E$ is determined by the initial condition: $w(0)=w_{i}$.

The gas temperature is then deduced from the enthalpy and the absolute humidity by:

$$
T_{g}(z)=\frac{h(z)-L_{v} w(z)}{C p_{g}}
$$

If the sub-domain $\Delta v$ of height $\Delta z$, in which $C^{*}, A^{*}$ and $\mu$ stay constant, could not be extended to the whole volume of the exchanger, it would be necessary to divide the exchanger into separate sub-domains and apply successive solutions, the exit of a sub-domain being the entrance of the next one.

\subsection{Simple analytical solutions}

Meaningful informations are derived from the ideal situation where the whole exchanger is treated as one single sub-domain with constant values for $C^{*}$ and $A^{*}$. This means that the equations are valid for the whole range $0<\mathrm{z}<Z$.

In that case, the solutions of equations (27) and (28) can take analytical forms for some discrete values of $\mu$ which happen to simplify the hypergeometric function $F$. We then get a global view of all possible operating modes of the exchanger by refering to asymptotic behaviors of these analytical forms. Two separate classes of solutions must be distinguished depending on the relative energy content of the gas and the liquid.

\subsubsection{Liquid phase imposes its rule: $\mu<1$}

This case is illustrated by thet value $\mu=0.5$, which gives for $w$ the analytical form:

$$
\begin{aligned}
w-w^{*}= & \frac{D}{N} e^{\left(\frac{-N z}{2}\right)}\left[2+e^{\left(\frac{-N z}{2}\right)}\left(\frac{N z}{2}+\ln (2)\right.\right. \\
& \left.\left.+\ln \left|1-\frac{e^{\left(\frac{-N z}{2}\right)}}{2}\right|+\frac{N}{D}\left(w_{i}-w_{i}^{*}\right)-2\right)\right] .
\end{aligned}
$$

The asymptotic behavior of $\mathrm{w}$ for large $z$ is then:

$$
w-w^{*}=\frac{e^{\left(\frac{-N z}{2}\right)}}{2\left[\left(C p_{g} / A^{*}\right)+L_{v}\right]}\left(h_{g i}-h_{i}^{*}\right) .
$$

The enthalpy difference $h_{g}-h^{*}$ reads:

$$
h_{g}-h^{*}=\frac{e^{\left(\frac{-N z}{2}\right)}}{2} \frac{1}{1-e^{\left(\frac{-N z}{2}\right)} / 2}\left(h_{g i}-h_{i}^{*}\right)
$$

leading to a first order expansion, valid for large $z$ :

$$
h_{g}-h^{*}=\frac{e^{\left(\frac{-N z}{2}\right)}}{2}\left(1+\frac{e^{\left(\frac{-N z}{2}\right)}}{2}\right)\left(h_{g i}-h_{i}^{*}\right) .
$$

The gas temperature, given by:

$$
T_{g}-T_{l}=\frac{1}{C p_{g}}\left[h_{g}-h^{*}-L_{v}\left(w-w^{*}\right)\right]
$$

behaves for large $z$ as:

$$
\begin{aligned}
T_{g}-T_{l}= & {\left[\frac{e^{\left(\frac{-N z}{2}\right)}}{2 C p_{g}}\right.} \\
& \left.\times\left(\frac{e^{\left(\frac{-N z}{2}\right)}}{2}+\frac{C p_{g}}{C p_{g} / A^{*}+L_{v}}\right)\right]\left(h_{g i}-h_{i}^{*}\right) .
\end{aligned}
$$

This means that, for large $z,\left(w-w^{*}\right),\left(T_{g}-T_{l}\right)$ and $\left(h_{g i}-h_{i}^{*}\right)$ keep the same sign.

In addition, $\left(w-w^{*}\right)$ and $\left(T_{g}-T_{l}\right)$ asymptotically vanish for large $z$, for any value of the enthalpic difference $\left(h_{g i}-h_{i}^{*}\right)$ of the entrance fluids.

\subsubsection{Gas flow imposes its law: $\mu>1$}

This case is illustrated with a value $\mu=2$, giving rise to the analytic form:

$$
\begin{aligned}
w-w^{*}= & \frac{D}{4 N}[2+\exp (-N z) \ln |1-2 \exp (N z)| \\
& \left.+\left(\frac{4 N}{D}\left(w_{i}-w_{i}^{*}\right)-2\right) \exp (-N z)\right]
\end{aligned}
$$

For large $z$, its asymptotic behavior is:

$$
w_{\infty}-w_{i}^{*}=\frac{D}{2 N}
$$

which also reads,

$$
w_{\infty}-w_{i}^{*}=-\frac{1}{\left(C p_{g} / A^{*}\right)+L_{v}}\left(h_{g i}-h_{i}^{*}\right) .
$$


The enthalpy reads

$$
h_{g}-h^{*}=-\frac{e^{N z}}{1-2 e^{N z}}\left(h_{g i}-h_{i}^{*}\right)
$$

which has the asymptotic behavior:

$$
h_{g \infty}-h^{*}=\left(h_{g i}-h_{i}^{*}\right) .
$$

The asymptotic temperature difference between the two fluids, at the upper end of a long exchanger, is then given by:

$$
T_{g \infty}-T_{l}=\frac{1}{C p_{g}}\left(1+\frac{L_{v}}{\left(C p_{g} / A^{*}\right)+L_{v}}\right)\left(h_{g i}-h_{i}^{*}\right) .
$$

Therefore, here again, for large $z\left(w_{\infty}-w^{*}\right),\left(T_{g \infty}-T_{l}\right)$ and $\left(h_{g i}-h_{i}^{*}\right)$ keep the same sign. But the humidity and temperature gaps do not tend to zero for large $z$ in this case.

\subsubsection{Discussion}

We can deduce from this analytical approach a general discussion on the nature of the process taking place in the regenerator, provided that the physical properties of the fluids stay invariant and that the temperature and the concentration of the liquid vary weakly along $z$.

For a long exchanger (in the $z$ direction), and independently of the value of $\mu$, the humidity difference $\left(w-w^{*}\right)$ and the temperature difference $\left(T_{g}-T_{l}\right)$ of the outgoing gas are proportional to $\left(h_{g i}-h_{i}^{*}\right)$ and of the same sign. This can be summarized by the equations:

$$
h_{g i}-h_{i}^{*}=\alpha\left(T_{g \infty}-T_{l i}\right)=\beta\left(w_{\infty}-w_{i}^{*}\right)
$$

with positive values for $\alpha$ and $\beta$.

If $\left(h_{g i}-h_{i}^{*}\right)$ vanishes at the entrance, then equation (18) implies that the transfert is isenthalpic:

$$
h_{g i}=h_{g o}=h_{i}^{*}=h_{o}^{*}=C t e
$$

But $h^{*}$ is constant only if $T$ stays constant (considering a nearly constant TEG concentration). It thus appears that, for a gas entering the exchanger at temperature $T_{g i}$ with a humidity content $w_{i}$, there exists some sort of "invariant" temperature limit for the liquid, independent of the fluid flow ratio $\mu$.

This "invariant" liquid temperature, $T_{l}=T_{i n v}$, characterizes an equilibrium situation which separates two classes of operating conditions.

Figures 5 to 7 illustrate the behavior of the fluids in all situations.

1) $1 h_{g i}-h_{i}^{*}=0$

The temperature of the liquid TEG is just at the equilibrium $\left(T_{i n v}\right.$ is in coincidence with $\left.T_{l}\right)$. Figures $5 \mathrm{a}$ and $5 \mathrm{~b}$ show the variation of temperature of the $\mathrm{flu}-$ ids and the humidity contents $w$ and $w^{*}$, as a function of position $z$ in the exchanger, for this isenthalpic situation. The shape of the curves is independent of the nature of the dominant fluid.
2) $h_{g i}-h_{i}^{*}<0$

As $T_{i n v}<T_{l}$ the incoming liquid TEG cools down. From equation (41), it appears that, whatever the dominant fluid, the gas leaves the exchanger with the following properties:

$$
w_{\infty}<w_{i}^{*} \text { and } T_{g \infty}<T_{l i}
$$

For large $z$, the gaps $(w-w)^{*}$ and $\left(T_{g}-T_{l}\right)$ tend to zero for $\mu<1$, but they keep finite values for $\mu>1$.

Figures $6 \mathrm{a}$ and $6 \mathrm{~b}$ summarize these situations.

3) $h_{g i}-h_{i}^{*}>0$

As $T_{i n v}>T_{l}$, the temperature of the TEG increases on its way down. In this case, equation (41) predicts the following asymptotic behaviour:

$$
w_{\infty}>w_{i}^{*} \text { and } T_{g \infty}>T_{l i}
$$

Figures $7 \mathrm{a}$ and $7 \mathrm{~b}$ summarize the situation according to $\mu$.

In the present situation, it is clear that there is a danger that $w$ goes through a maximum and then decreases through the later part of the exchanger.

From this discussion, we can deduce that it is recommanded to feed the counterflow exchanger with a liquid TEG warmer than the isenthalpic temperature limit $T_{i n v}$.

This soluble model is based on the assumption that the slopes $C^{*}$ and $A^{*}$ of the saturation curves can be considered constant throughout the considered volume of the exchanger. This is not strictly correct, since the TEG concentration of the liquid increases on its way down and modifies its isenthalpic "invariant" temperature. But the TEG concentration change in the regeneration process is very weak in practice (it increases by only $1 \%$ in one pass through the exchanger), so that it has little effect. On the other hand, the temperature of the liquid could undergo some drastic change through the exchanger if its entrance value happens to be too far from the "invariant" value. A more exact numerical approach will then be necessary to account for such a process.

\subsection{Numerical resolution in the general case}

A numerical resolution of the equations allows to relax the constraint set on $C^{*}$ and $A^{*}$ and to take into account possible changes in temperature and concentration of the liquid TEG through the exchanger. The equations used in the numerical simulation are presented now.

From equation (15):

$$
d\left(h_{g}-h^{*}\right)=\left(h_{g}-h^{*}\right)(\mu-1) e^{-(1-\mu) N z} d z
$$

and from equation (2), combined with equation (9) and (11):

$$
d\left(h_{g}-h^{*}\right)=\left(\frac{L}{G} C p_{l}-C p_{g}-L_{v} A^{*}\right) d T_{l}
$$

one gets an equation for the liquid TEG temperature:

$$
\frac{d T_{l}}{d z}=\frac{\left(h_{g}-h^{*}\right)(\mu-1) N e^{-(1-\mu) N z}}{\left(\frac{L}{G} C p_{l}-C p_{g}-L_{v} A^{*}\right)} .
$$




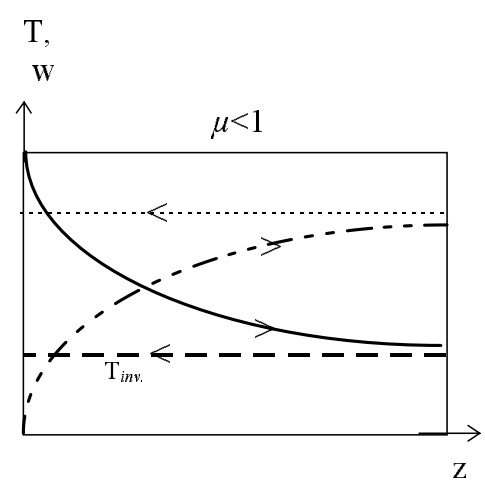

(a)

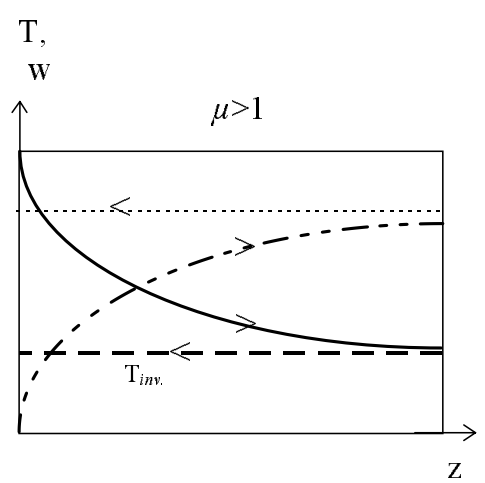

(b)

Fig. 5. Isenthalpic exchange in a counterflow configuration with $h_{g i}-h_{i}^{*}=0$. (a) Liquid dominant; (b) Gas dominant. Symbols: $-T_{g},---t_{l},---w,--w^{*},---T_{i n v}$.

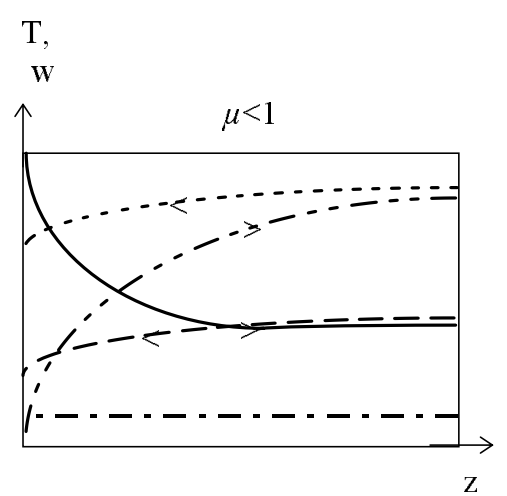

(a)

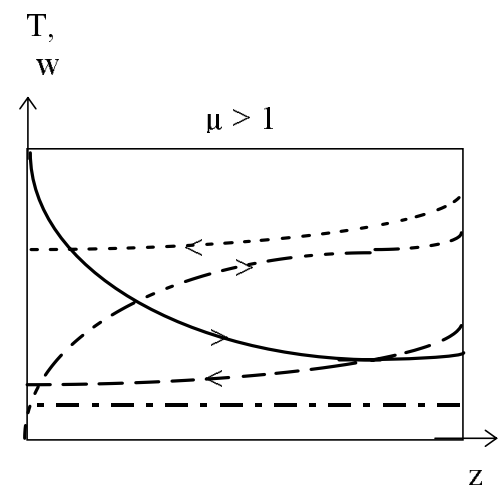

(b)

Fig. 6. Non-isenthalpic exchange in a counterflow configuration with $h_{g i}-h_{i}^{*}<0$. (a) Liquid dominant; (b) Gas dominant.

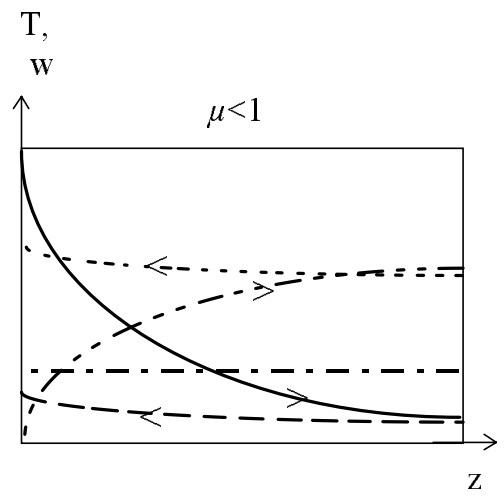

(a)

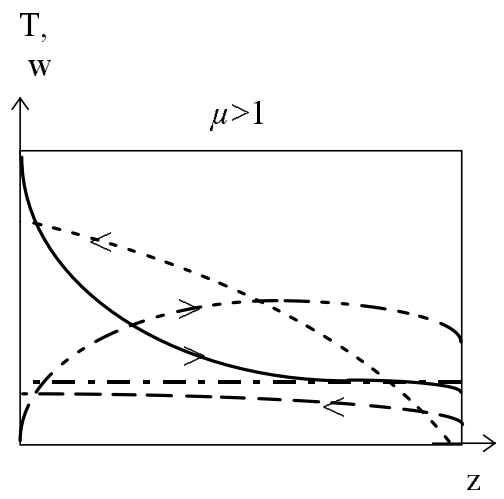

(b)

Fig. 7. Non-isenthalpic exchange in a counterflow configuration with $h_{g i}-h_{i}^{*}>0$. (a) Liquid dominant; (b) Gas dominant.

Equation (23) gives the humidity content $\mathrm{w}$ of the gas:

$$
\frac{d\left(w-w^{*}\right)}{d z}+N\left(w-w^{*}\right)=\frac{\mu}{\left(C p_{g} / A^{*}\right)+L_{v}}\left(h-h^{*}\right)
$$

This set of equations was solved by discretization with no other approximation than keeping constant $C p$ values for the gas and the liquid. As the exchanges take place in a counterflow mode, an additional difficulty arises: solv- ing these equations is an inverse problem which requires a trial and error procedure to obey entrance conditions. A tentative guess is made for the outlet liquid temperature (at $z=0$ ), where the inlet gas conditions are known. One proceeds to solve the equation step by step up to the top of the exchanger $(z=Z)$. The procedure is repeated until agreement is found between the imposed TEG temperature at the top and the calculated TEG temperature at $z=Z$. 
Table 2. Working conditions simulated in the regenerators.

\begin{tabular}{lll}
\hline$\stackrel{\circ}{m}_{g}$ & Gas rate & $0.150 \mathrm{~kg} \mathrm{~s}^{-1}$ \\
$\stackrel{\circ}{m}_{l}$ & TEG solution rate & $0.400 \mathrm{~kg} \mathrm{~s}^{-1}$ \\
$T_{g i}$ & Input gas temperature & 80 to $140{ }^{\circ} \mathrm{C}$ \\
$w_{i}$ & Input gas temperature & 40 to $52 \mathrm{~g} \mathrm{~kg}_{\text {gas }}^{-1}$ \\
$T_{l i}$ & Input TEG solution temperature & 64 to $69^{\circ} \mathrm{C}$ \\
\hline
\end{tabular}

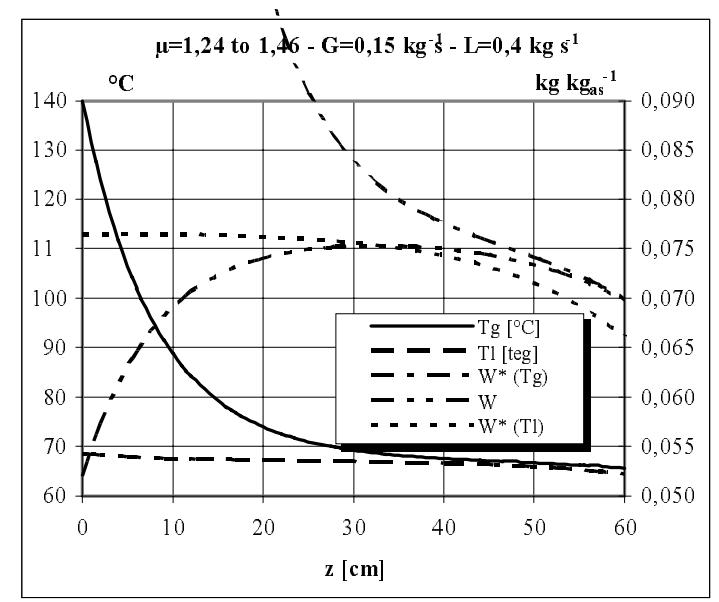

Fig. 8. Gas temperature and humidity.

To prevent numerical oscillations and improve convergence, the resolution of the differential equations was done with a 4 th order Runge-Kutta formula which proved to be satisfactory.

\section{Remarks}

Just like in the analytical model, it may happen that the temperature of the incoming liquid TEG is close to the "invariant" isenthalpic temperature; in that case, even a very small change of the guess value at $z=0$ can produce a strong TEG temperature change on the inlet side $(z=Z)$. This effect is illustrated by comparing $T_{l i}$ from Figures $6 \mathrm{a}$ and $7 \mathrm{a}$ or from Figures $6 \mathrm{~b}$ and $7 \mathrm{~b}$.

The approximation which amounts to ignore the variation of $T_{i n v}$ along the exchanger, as a result of the concentration change of the liquid TEG, will be entirely justified later by the weak evaporation rate relatively to the liquid TEG flow rate $\mathcal{L}$.

A similar numerical approach was applied to describe the gas washer, which uses pure water in counterflow with the gas to condense its humidity content. In that case, the isenthalpic temperature $T_{i n v}$ is a true constant.

\section{Numerical simulation of transfers in prototype No 1}

A first simulation of the heat and mass transfers in the regenerators was performed for operating conditions corresponding to the first prototype. They are indicated in the Table 2 .

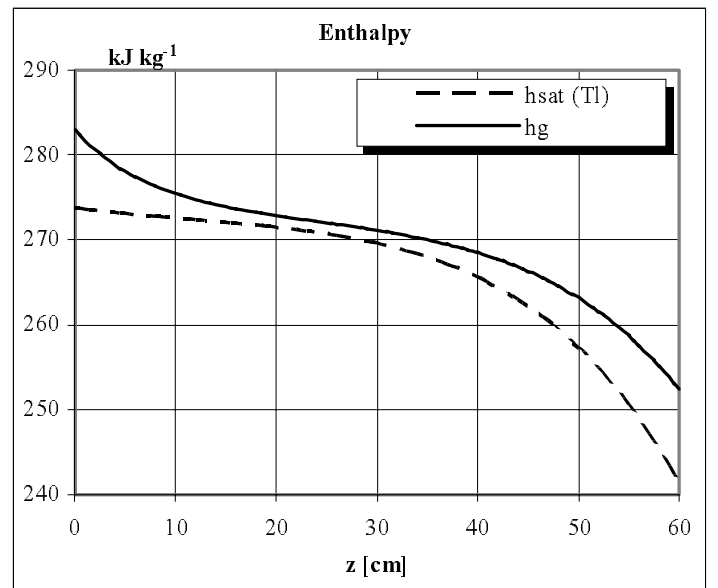

Fig. 9. Gas enthalpies $h_{g}$ and $h_{\text {sat }}$ (at TEG temperature).

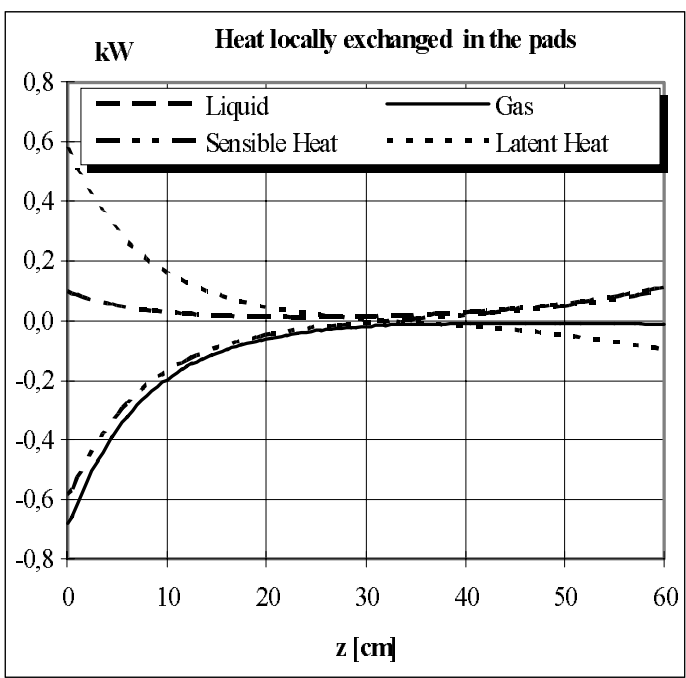

Fig. 10. Heat locally exchanged in the pads.

Considering the curves of Figures 8 and 9, the actual heat transfers occurring in prototype No 1 correspond to the case $h_{g e}-h_{e}^{*}>0$ (temperature of the incoming TEG below $T_{\text {inv }}$ ) and $\mu>1$ (gas dominant), illustrated by Figure $7 \mathrm{~b}$ in the soluble model. Most of the transfers occur through the first three pads $(30 \mathrm{~cm})$, and raise the humidity content of the gas from $52 \mathrm{~g} \mathrm{k}_{\text {gas }}^{-1}$ to $74 \mathrm{~g} \mathrm{k}_{\text {gas }}^{-1}$. In the 4 th pad, the $w$ and $w_{\text {sat }}$ curves cross each other and the direction of mass transfers thus reverses itself. From that point to the exit, the gas restitutes water to the TEG solution which happens to be too cold and hygroscopic.

This process reversal is confirmed by Figure 10 which shows the latent heat of evaporation going locally through zero in the course of the process. The heat transfer becomes negative when the TEG solution starts condensating water vapor from the gas.

Figure 11 indicates the direction of the heat transfers. One notices that the whole heat load is provided by the gas. In the lower part of the exchanger, pure sensible heat from the gas is used to evaporate water from the TEG solution. Upper on, the solution is heated by latent heat of condensation from the gas. Only in the two lower pads 


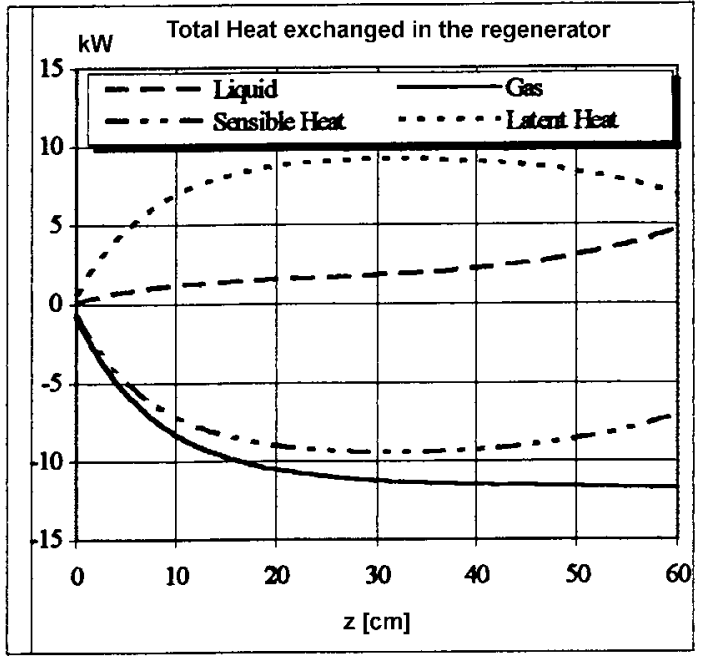

Fig. 11. Total cumulative heat exchanged in the regenerators.

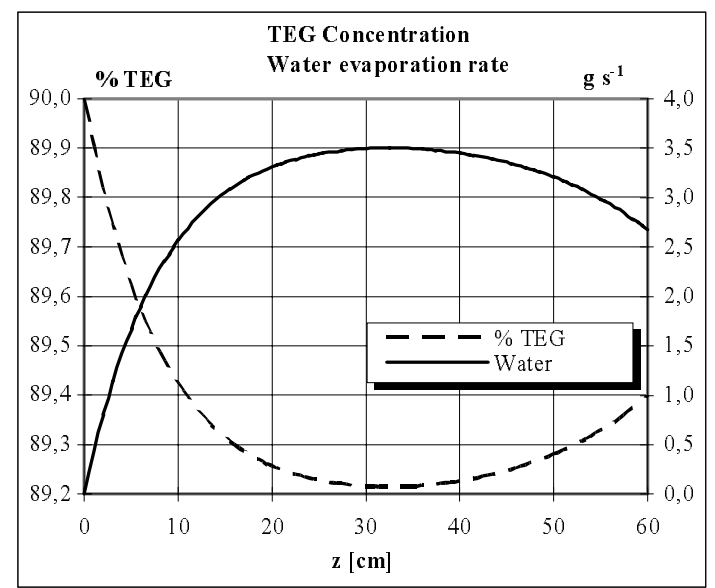

Fig. 12. TEG concentration and water evaporation rate as a function of position $z$ in the pads.

does the water vapor pressure from the TEG solution exceeds that of the gas: the two upper pads thus operate in the wrong way.

The $3 \mathrm{~g} \mathrm{~s}^{-1}$ water evaporation rate from the TEG, experimentally obtained for prototype No 1 in which six consecutive pads operate in a row, is confirmed by the result of the numerical simulation shown in Figure 12.

One learns from the simulation that the evaporation rate reaches a maximum $\left(3.5 \mathrm{~g} \mathrm{~s}^{-1}\right)$ after the third pad, but the three upper pads only contribute to decrease that rate. Two factors can be blamed for that:

- the input temperature of the TEG solution is too low; - the initial humidity content of the drying gas is too high.

It was not difficult to increase the temperature of the incoming TEG. But reducing the humidity content of the gas required a serious design modification which lead to the prototype No 2 described below.

Finally, it is instructive to see from the Figure 8 that the temperature of the TEG solution varies very little $\left(5{ }^{\circ} \mathrm{C}\right)$ along the regeneration process, while its concentration increases by $1 \%$ only. This confirms, a posteriori, the validity of the assumption that $A^{*}$ and $C^{*}$ stay sufficiently constant throughout the exchanger to permit a realistic discussion from the simplified analytical solutions.

\section{Modifications resulting in prototype No 2}

A special gas-gas counterflow plate exchanger able to stand high temperatures was designed [17]. Other modifications concerned the range of variation of the various mixing valves, so that optimum temperatures could be reached for both fluids.

One of the preliminary conditions was to keep the regenerators free from vibrations arising from the turbulent regime of the flames, and this specially during transient phases.

For the sake of simplicity, greenhouse heat and dehumidification loads were simulated:

$-40^{\circ} \mathrm{C}$ water at a rate of $81 \mathrm{~s}^{-1}$ reproduced the return flow from a $1000 \mathrm{~m}^{2}$ heated greenhouse;

- a $60 \mathrm{l}$ tank of diluted (90\% proof) TEG was placed on a scale (precision $10 \mathrm{~g} / 100 \mathrm{~kg}$ ) to simulate the return TEG flow from dehumidifying pads.

The concentration of the TEG solution was allowed to increase during the regeneration process, so that various inlet TEG concentrations could be studied during a single run. The rate of water evaporation from the TEG was deduced from the scale readings.

The inlet gas temperature was kept around $90{ }^{\circ} \mathrm{C}$ to prevent the production of TEG vapors.

\section{Experimental results on the prototype No 2}

\subsection{Experimental set up}

The sketch of the 2 nd prototype of TEG regenerators is shown in Figure 13.

The initial concentration of the TEG solution was set at $90 \%$, because this corresponds to a good desiccant efficiency of the dehumidifying pads [15]. At the end of a given run, the concentration could reach $96 \%$, which corresponds to a much more hygroscopic fluid than necessary and to unusually restrictive conditions for the regeneration process. The regeneration process had to be adapted to increasing concentrations of the TEG solution by a progressive increase of the inlet TEG temperature. This is illustrated by the curves presented in Figure 14 .

When the temperature of the liquid TEG changes, so does its viscosity. The reading of the scale is then temporarily altered by the change of the liquid fraction which stays adherent to the walls of the exchanger. Therefore, if one takes into account the progressive temperature rise of the fluids shown in the later part of the test, the actual regeneration rate is probably underestimated by the dotted curve shown in Figure 15.

During the first part of the test shown in Figure 15, and after a transient regime, the water extraction rate 


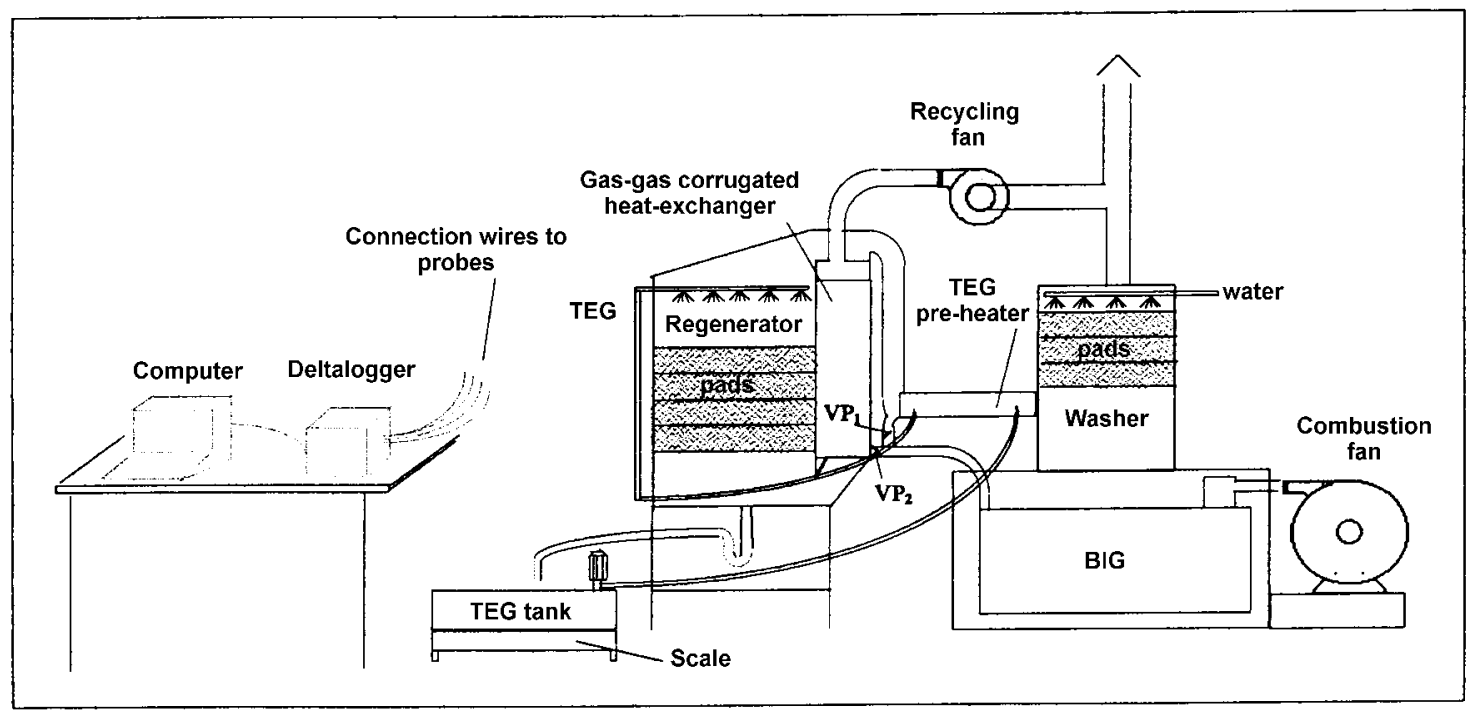

Fig. 13. Sketch of the modified dehumidifier prototype No 2 .

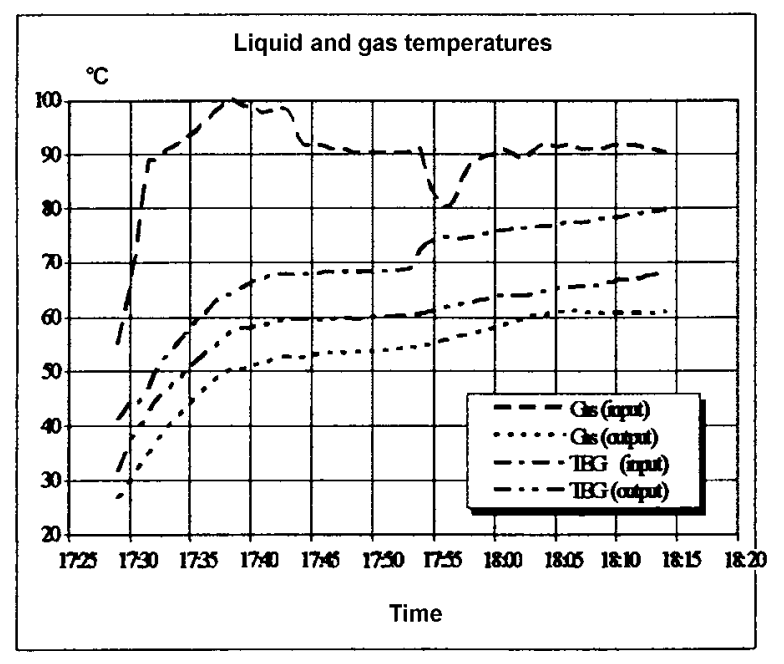

Fig. 14. Gas and TEG temperatures at the regenerators input and output.

reaches a maximum above $5 \mathrm{~g} \mathrm{~s}^{-1}$ when the input temperature of the gas is set at $100{ }^{\circ} \mathrm{C}$. Over that period, the TEG concentration steadily increases from $90 \%$ to $92 \%$. During the second part of the test, the gas temperature is kept around $90^{\circ} \mathrm{C}$ and the temperature of the TEG solution is progressively raised at $80^{\circ} \mathrm{C}$. The extraction rates decreases and stabilizes around $4 \mathrm{~g} \mathrm{~s}^{-1}$. But this time, the concentration of the TEG solution rises from $92 \%$ to $96 \%$. Given the strong hygroscopicity of TEG at such concentrations and the tendency to underestimate the extraction rate, one can be amply satisfied with the performance.

We thus predict a mean regeneration rate of more than $5 \mathrm{~g} \mathrm{~s}^{-1}$ for the typical $90-92 \%$ concentration range of the TEG dessicant solution used for greenhouse dehumidification. As the TEG flow rate is $0.4 \mathrm{~kg} / \mathrm{s}$, the change in TEG concentration along its path does not exceed $1.5 \%$, a small

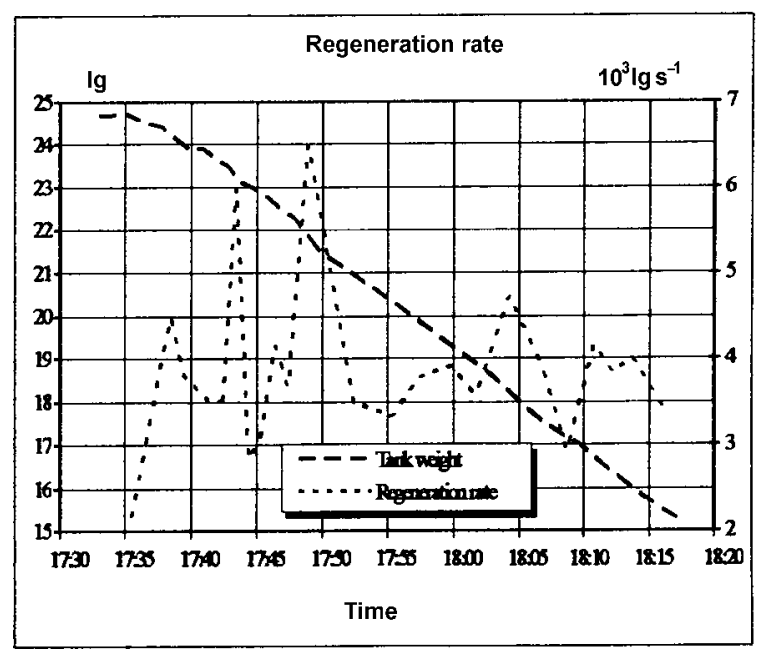

Fig. 15. Variation of the TEG tank weight and regeneration rate.

fluctuation which supports the simplifying hypothesis in the analytical approach of the problem.

\section{Numerical simulation of transfers in the prototype No 2}

The working conditions for prototype No 2 are different. The TEG solution is preheated at $70-80^{\circ} \mathrm{C}$ with a lower flow rate. The inlet gas temperature is reduced to $90^{\circ} \mathrm{C}$ to prevent TEG vapor losses and the gas flow rate was increased.

Figures $16 \mathrm{a}-16 \mathrm{~b}$ and $17 \mathrm{a}-17 \mathrm{~b}$ show the temperatures of the fluids and the enthalpy of the gas inside the regenerators obtained by the numerical simulation. Curves (a) refer to conditions of a first regime (inlet TEG at $70^{\circ} \mathrm{C}$ ) and curves (b) to conditions of a second regime (inlet TEG at $\left.80^{\circ} \mathrm{C}\right)$. 


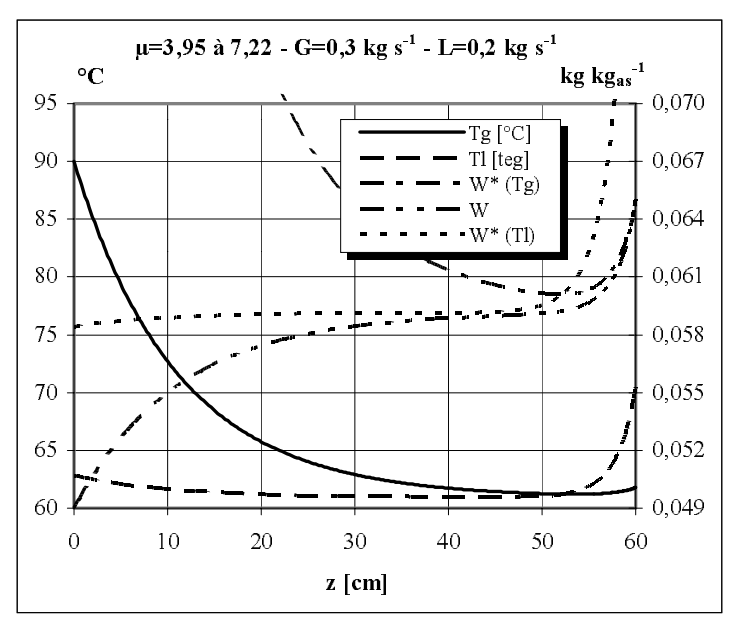

(a)

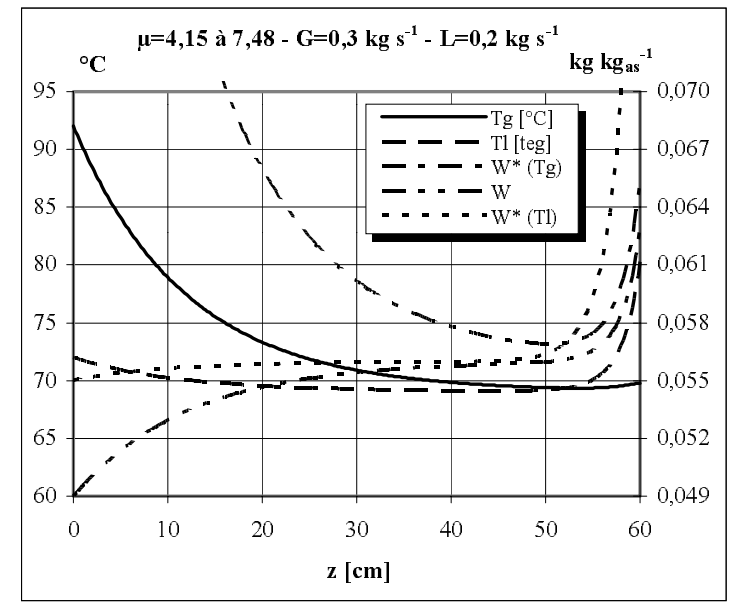

(b)

Fig. 16. (a) and (b): Heat locally exchanged in the regenerators for two different regimes.

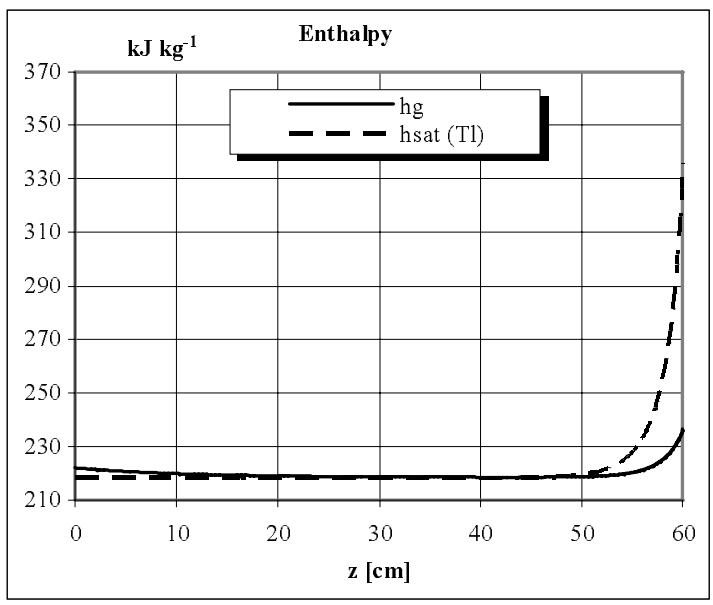

(a)

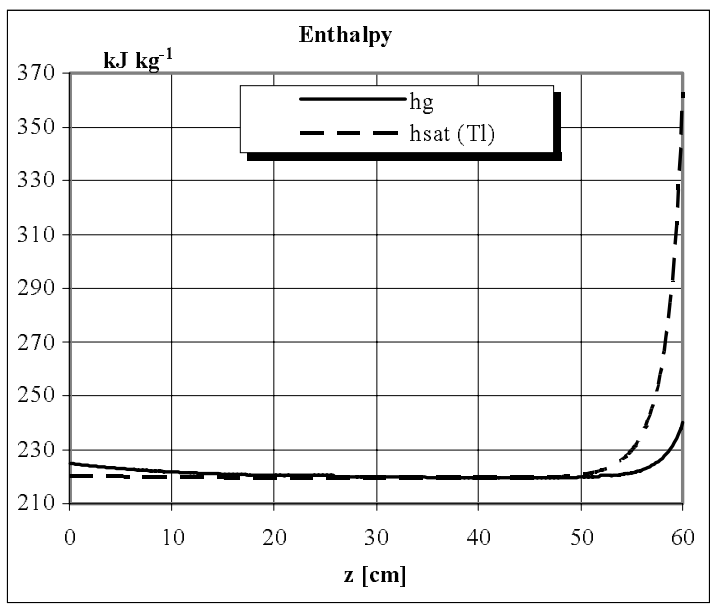

(b)

Fig. 17. (a) and (b): Enthalpies $h_{g}$ and $h_{\text {sat }}$ at the TEG temperature for two different regimes.

Both conditions corresponds to a process with $\left(h_{g i}-\right.$ $\left.h_{i}^{*}<0\right)$, and the temperature of the TEG is higher than the isenthalpic limit $T_{i n v}$ at the entrance.

As predicted by the analytical model (Fig. 6b), one observes a cross-over in the temperatures of the fluids in the upper part of the exchanger: this indicates that the evaporation process stays efficient up to the top of the exchanger. The experimental values of Figure 14 are confirmed by the simulations of Figure 16a and 16b. The drying gas leaves the exchanger cooler then the incoming TEG in both regimes (a) and (b).

The enthalpy curves shown in Figure $17 \mathrm{a}$ and $17 \mathrm{~b}$ show that most of the water extraction process occurs in the two lower pads (first $20 \mathrm{~cm}$ ) and in the last pad (last $10 \mathrm{~cm}$ ). The heat for evaporation is provided, at the bottom, by the gas, and, at the top, by the TEG solution.

Equation (5) indicates that the water extraction rate is proportional to the gap $\left(w^{*}-w\right)$. From Figure 16a and $16 \mathrm{~b}$, it can be seen that the water extraction rate is larger in the lower pads, for the regime (a), where the gap is larger than in the regime (b); but, in the upper pads, the situation is reversed.

This is confirmed by the curves of Figure 18a and 18b which show the latent heat of evaporation in both cases.

Between the 4 th and 5 th pads (i.e. between $30 \mathrm{~cm}$ and $50 \mathrm{~cm}$ ), there is little transfer between the fluids, because the gap $\left(w^{*}-w\right)$ is close to zero and the temperatures of the fluids do not differ much.

In the last pad (between $50 \mathrm{~cm}$ and $60 \mathrm{~cm}$ ), the humidity gap $\left(w^{*}-w\right)$ becomes important again, but the gas temperature is too low to capture much vapor.

\section{Remarks}

One can get an insight on the validity of the approximation made in the analytical model (where $A^{*}$ and $C^{*}$ are kept constant throughout the exchanger volume): as seen in Figure 16, $w^{*}$ stays roughly constant from $z=0$ to $z=50 \mathrm{~cm}$ but start increasing in the last pad. Therefore, the approximation may be less justified in the upper part of the exchanger, where the temperature of the liquid changes very rapidly within a short distance. 


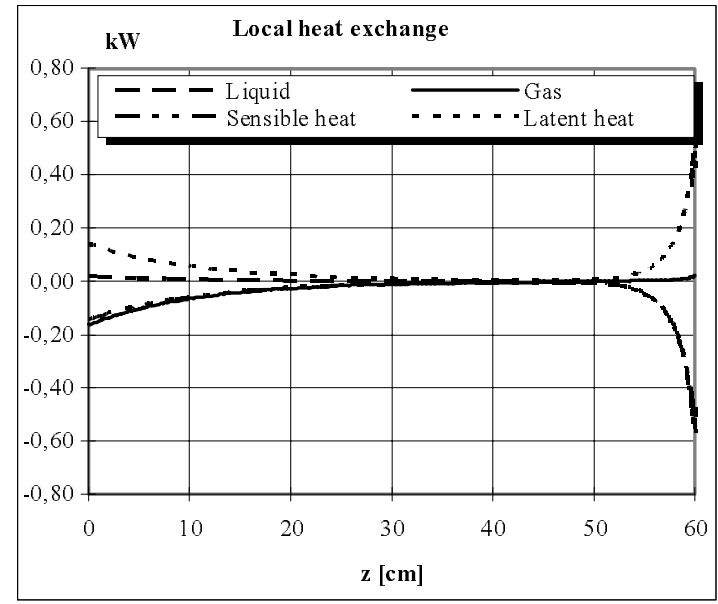

(a)

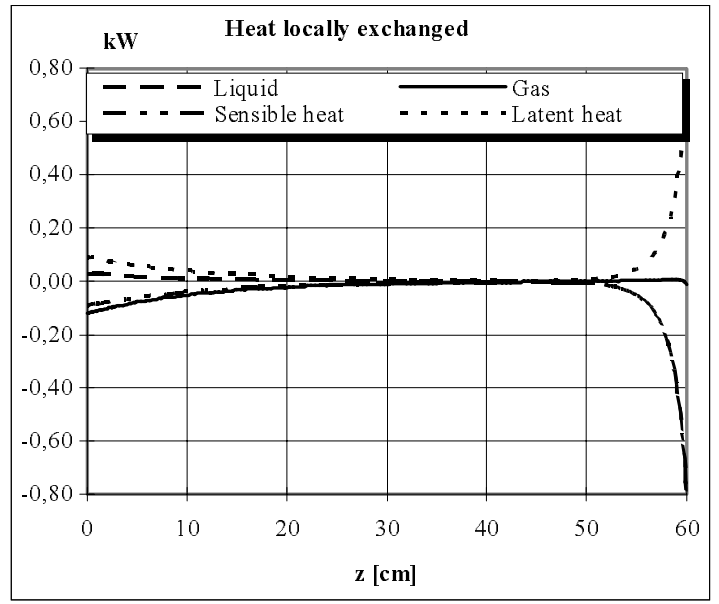

(b)

Fig. 18. (a) and (b): Heat locally exchanged in the regenerators for two different regimes.

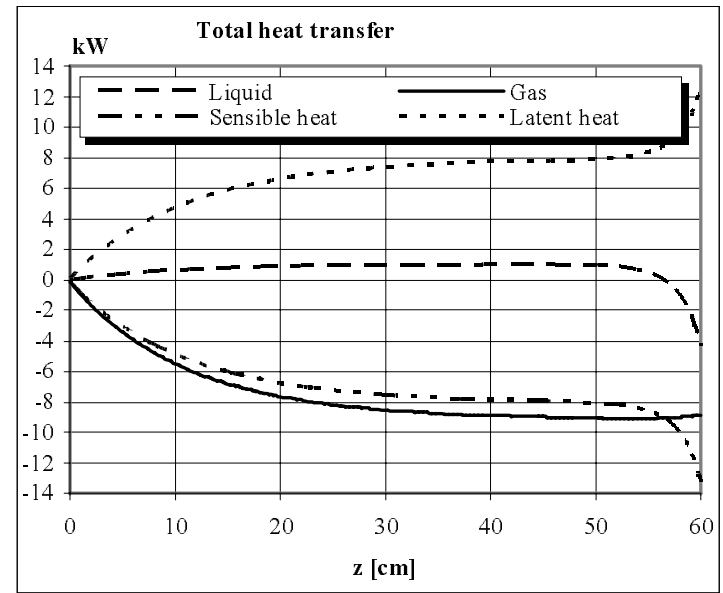

(a)

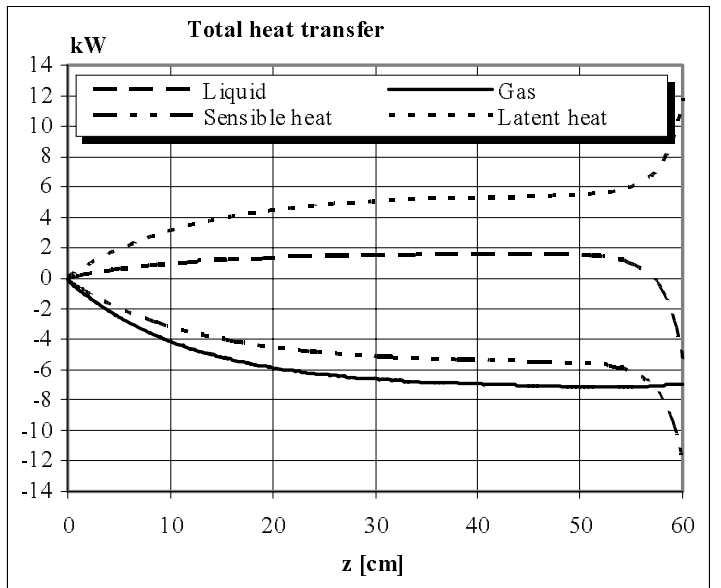

(b)

Fig. 19. (a) and (b): Total heat exchanged in the regenerators for two different regimes.

The $w^{*}$ curves (saturating humidity content at $T_{g}$ or $T_{L}$ ) in Figure 17a are very similar to those of Figure $17 \mathrm{~b}$. This is due to two compensating effects: at a higher temperature, like in regime (b), the vapor pressure, or $w^{*}$, should be higher; but at the same time, the TEG concentration is stronger, which tends to decrease the corresponding equilibrium vapor pressure.

The two regimes (a) and (b) give therefore similar results; but they are not obtained in the same manner: in regime (a), most of the water extraction is achieved in the first 3 pads, and very little in the last pad (Fig. 20a); in regime (b), on the contrary, the last pad provides a an equally important contribution (Fig. 20b).

\section{Conclusion}

The different modifications brought to the TEG regenerators design in the prototype No 2 were sufficient to improve its performance and to provided the desired re- sults: it gave a water extraction rate up to $6 \mathrm{~g} \mathrm{~s}^{-1}$, with a return water temperature of $40^{\circ} \mathrm{C}$ at the washer, the gas temperature being kept around $90^{\circ} \mathrm{C}$ for the sake of security (absence of TEG vapor emission). Such a performance was obtained with a TEG concentration even slightly higher than normal (92\% instead of $90 \%)$, without ever using the full power of the burner $(100 \mathrm{~kW}$ here instead of the $150 \mathrm{~kW}$ rated power). This proves that the configuration chosen in the second prototype is quite satisfactory and is able to meet the heat and dehumidification requirements of a $1000 \mathrm{~m}^{2}$ greenhouse. This new apparatus combines a usual boiler with a special regenerators for the dessicant fluid and can replace commercial condensation boilers commonly used in small greenhouses.

To define the proper design of the TEG regenerators, the detailed simulation of heat and mass transfers in a counterflow mode through the pads proved essential: a precise tuning of the temperatures of both fluids was necessary to avoid possible recondensation processes observed on the upper part of the pads of the first prototype. 


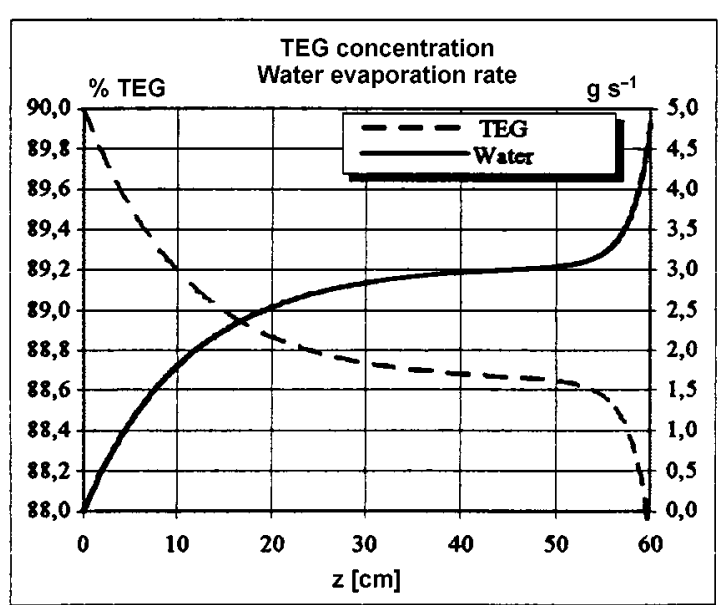

(a)

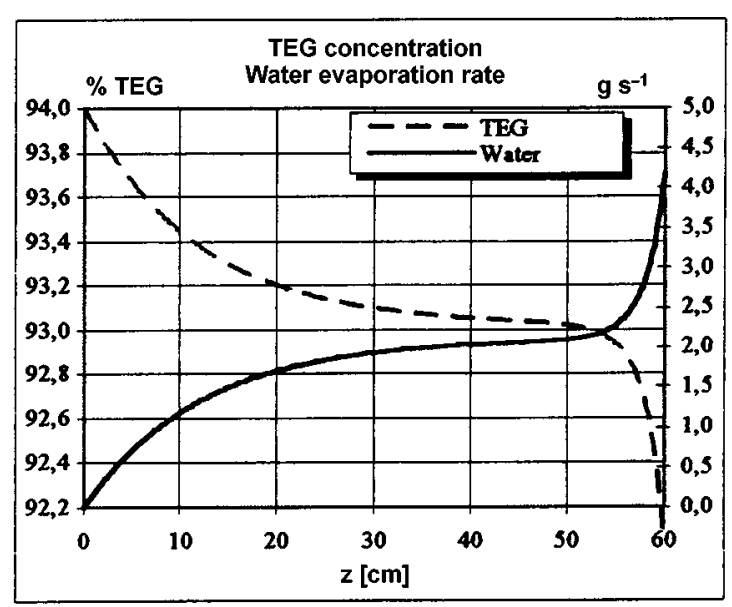

(b)

Fig. 20. (a) and (b): TEG concentration and water evaporation rate for two different regimes.

Checking various exchange modes through the extensive use of a simplified analytical model brought the crucial diagnostics on the first prototype and paved the way for a better design. More exact numerical simulations were then used to validate the diagnostics and to test the performance of the second prototype which proved in the end to be quite satisfactory.

\section{References}

1. H.M. Factor, G. Grossman, Sol. Energy 24, 541 (1980).

2. V.C. Mei, Z. Lavan, J. Sol. Energy Eng. 105, 300 (1983).

3. A. Samuel, M. Vedamurthy, in 3rd Intern. Congress on Engineering and Food, Dublin, Ireland, edited by B. McKenna, Elsevier Appl. Sc. Publ. 29 1164, (1986).

4. M.R. Ullah, C.F. Kettelborough, P. Gandhidasan, J. Sol. Energy Eng. 110, 57 (1988).

5. R.G. Supple, ASHRAE J. 36 (1982).

6. K.G.T. Hollands, Mechanical and Chemical Engineering Transactions. Report $\mathrm{N}^{\circ} 2939,55,1970$.
7. A. Chraibi, S. Makhlouf, A. Jaffrin, N. Bentounes, J. Phys. III France 5, 1039 (1995).

8. J.J. Jurinak, J.W. Mitchell, W.A. Beckman, J. Sol. Energy. Eng. 106, 252 (1984).

9. S. Patnaik, T.G. Lenz, G.O.G. Löf, Sol. Energy. 44123 (1990).

10. M. Dupont, B. Celestine, P.H. Nguyen, J. Merigoux, B. Brandon, Sol. Energy. 52, 509 and 519 (1994).

11. T. Boulard, A. Baille, J. Lagier, M. Mermier, E. Vanderschmitt Proc. International Conference on Agricultural Engineering, report $\mathrm{N}^{\circ} 88.369$ (1988).

12. G. Assaf, Heat Recovery Systems 6, 369 (1986).

13. A. Chraibi, Ph.D., thesis University of Nice-Sophia Antipolis, 1994.

14. A. Chraibi, A. Jaffrin, N. Bentounes, P. Blondeau, Entropie 188/189, 83 (1995).

15. A. Chraibi, A. Jaffrin, S. Makhlouf, N. Bentounes, J. Phys. III France 5, 1055 (1995).

16. D.I. Stevens, J.E. Braun, Klein, Sol. Energy 42, 449 (1989).

17. N. Bentounes, Ph.D. thesis, University of Nice-Sophia Antipolis, 1997.

18. A. Amblard, Ph.D. thesis, INPG Grenoble, 1986. 